\title{
Erratum to: Effect of temperature difference between manikin and wet fabric skin surfaces on clothing evaporative resistance: how much error is there?
}

\author{
Faming Wang • Kalev Kuklane • Chuansi Gao • \\ Ingvar Holmér
}

Published online: 26 November 2011

(C) ISB 2011

Erratum to: Int J Biometeorol

DOI 10.1007/s00484-011-0411-z

On the fourth page, there are errors in the data (the values were by mistake multiplied by the magnitude of the fabric skin sweating area $A=1.426 \mathrm{~m}^{2}$ ) in Fig. 1. The Fig. 1 should be presented as follows:
On the fourth page, lines 2-6 (the left column), the mean real evaporative resistance of the boundary air layer should be $0.0203 \mathrm{kPa} \mathrm{m} / \mathrm{W}$ (the previously presented value divided by $A=1.426 \mathrm{~m}^{2}$ ), and the averaged evaporative resistance calculated from the manikin surface temperature should be $0.0249 \mathrm{kPa} \mathrm{m}^{2} / \mathrm{W}$.

We wish to thank Prof. George Havenith at Loughborough University, UK, for pointing out the errors.

Fig. 1 The evaporative resistances of the boundary air layer calculated from the manikin nude surface temperature and the wet textile skin surface temperature (by the heat loss option). Rea_real The real evaporative resistance of the air layer calculated from the wet skin

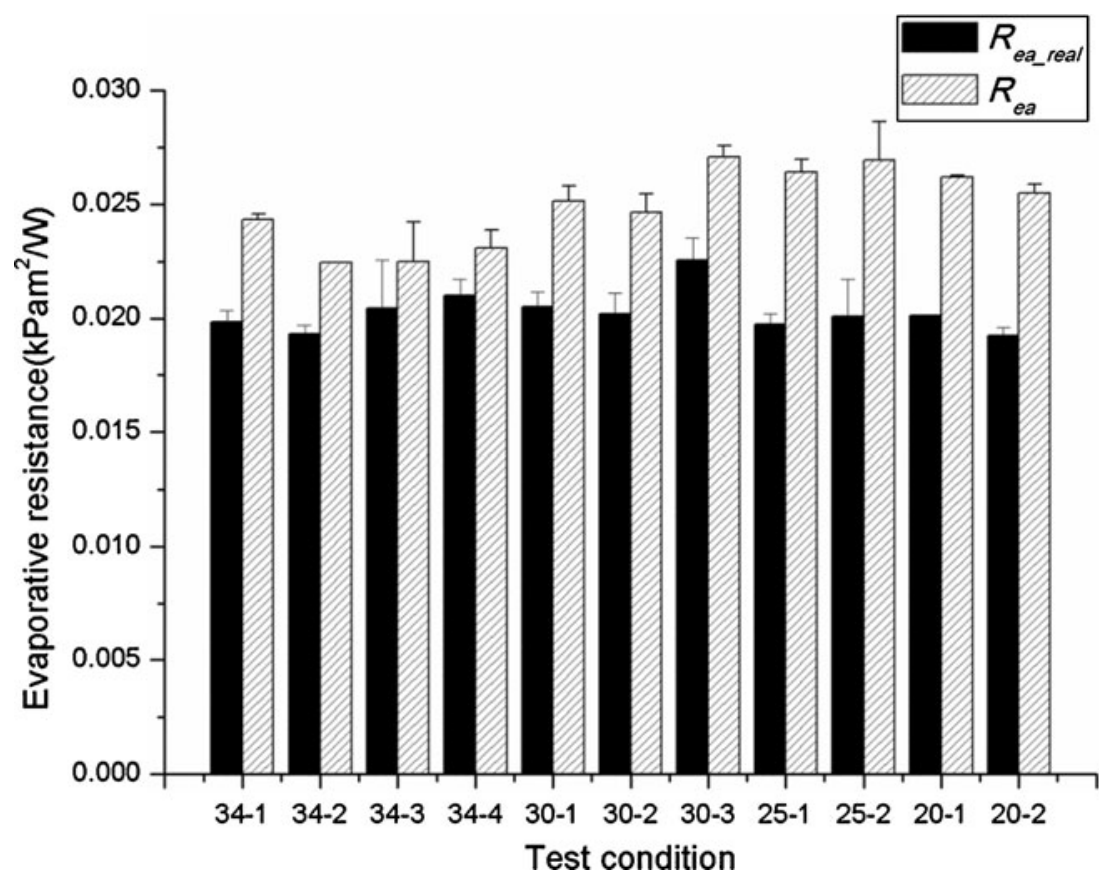

The online version of the original article can be found at http://dx.doi. org/10.1007/s00484-011-0411-z.

\footnotetext{
F. Wang $(\bowtie) \cdot$ K. Kuklane $\cdot$ C. Gao $\cdot$ I. Holmér

Thermal Environment Laboratory, Division of Ergonomics and Aerosol Technology, Department of Design Sciences, Faculty of Engineering, Lund University, 22100 Lund, Sweden e-mail: faming.wang@design.lth.se
} 